\title{
Numerical Predictions and Experimental Observations of the Structural Response of Steel Columns to High Temperatures
}

\author{
D.J. BAKER and Y.M. XIE \\ Department of Civil and Building Engineering \\ Victoria University of Technology \\ PO Box 14428, MCMC, Melbourne VIC 8001 Australia \\ P.H. DAYAWANSA \\ BHP Research-Melbourne Laboratories \\ 245-273 Wellington Road \\ Mulgrave VIC 3170 Australia
}

\begin{abstract}
The response of structural steel columns to high temperatures is investigated. Both numerical prediction and experimental testing are carried out. The material properties of the steel are obtained from a series of tensile coupon tests at various temperatures and two different strain rates. A high strain rate was used to determine instantaneous material properties, while a low strain rate allowed some creep strain to be included implicitly. These strain rate dependent material properties are incorporated in a finite element analysis (FEA) to simulate the results of stub column buckling tests, conducted at range of temperatures up to $600^{\circ} \mathrm{C}$. Good agreement has been obtained between the numerical simulations and the tests.
\end{abstract}

KEYWORDS: steel column, fire, material properties, creep, buckling, testing

INTRODUCTION

Australia has a very good fire safety record, but this has been achieved at high costs for building construction, which are imposed by prescriptive and conservative building regulations. The move toward a rational engineering approach to fire engineering design was advocated during the Warren Centre project [1]. Rational methods of fire design based on real fires will in many situations be less severe than conditions assumed at present. Other methods of fire protection such as sprinklers, when properly designed, have been found to be very effective. This approach can lead to lower levels of fire protection, and hence lower cost. In 
certain cases passive fire protection can be eliminated altogether. One example where a rational approach based on testing resulted in no passive protection is the use of unprotected steelwork in carparks [2].

If passive fire protection in buildings other than carparks is to be significantly reduced, it is necessary to model and predict the behaviour of structural members under the relevant conditions. One of the major aims of this project is to determine the significance of local buckling, the post buckled response, and high temperature creep for unprotected steel columns subjected to high fire loads in small compartments, where intense fires may develop; for example in partitioned office or residential accommodation. Neglecting the effects of creep and local buckling, particularly creep, is an assumption which has been made in many past studies of steel columns exposed to fire, such as those by Culver et al. [3], Burgess et al. [4], and Olawale and Plank [5].

This paper investigates the local buckling and post buckling response of steel columns at elevated temperatures, and details a method of accounting for these time dependent effects by implementing rate dependent material properties into a finite element analysis (FEA). The material properties used in the analysis are obtained from a series of elevated temperature tensile tests, while a series of stub-column buckling tests are used to validate the FEA simulations. Time is incorporated by setting the total time of the analysis equal to the total time of a test, or the duration of a fire, with known steel temperatures at each time or load increment. This method has the major advantage of being very easy to implement.

The stub columns were tested at constant temperatures using displacement control. These conditions do not apply to a restrained column in a multi-storey building exposed to fire, where localised heating of columns on one fire-affected level is the most probable outcome, as observed in the Broadgate Phase 8 fire of June 23rd, 1990 [6]. A series of elevated temperature creep tests have been carried out to determine relevant creep data, which is currently being incorporated into a FEA model to analyse a real column. This work is not reported in this paper.

\section{TESTS}

\section{$2.1 \quad$ Tensile Coupon Tests}

A series of 38 elevated temperature tensile tests were carried out at BHP Research Melbourne Laboratories (BHPR-ML) using a $25 \mathrm{KN}$ Sintech screw actuator testing machine. A schematic of the test setup is shown in Figure 1.

The tests were carried out at two strain rates, $0.2 \mathrm{~mm} / \mathrm{mm} / \mathrm{min}$ and $0.002 \mathrm{~mm} / \mathrm{mm} / \mathrm{min}$, at temperatures of $20^{\circ} \mathrm{C}, 200^{\circ} \mathrm{C}, 300^{\circ} \mathrm{C}$, and then in $50^{\circ} \mathrm{C}$ increments to $650^{\circ} \mathrm{C}$. The $0.2 / \mathrm{min}$ strain rate was chosen to give "instantaneous" stress-strain data, while the $0.002 / \mathrm{min}$ strain rate was chosen to represent a strain rate that may be experienced by a column in a real fire, ie, a slow strain rate that implicitly includes some deformation due to creep. The tensile coupons were cut from the flanges of a Grade 250 150UC23.4 universal column section, and then prepared and tested according to Australian Standard AS1391 - 1991 [7]. 


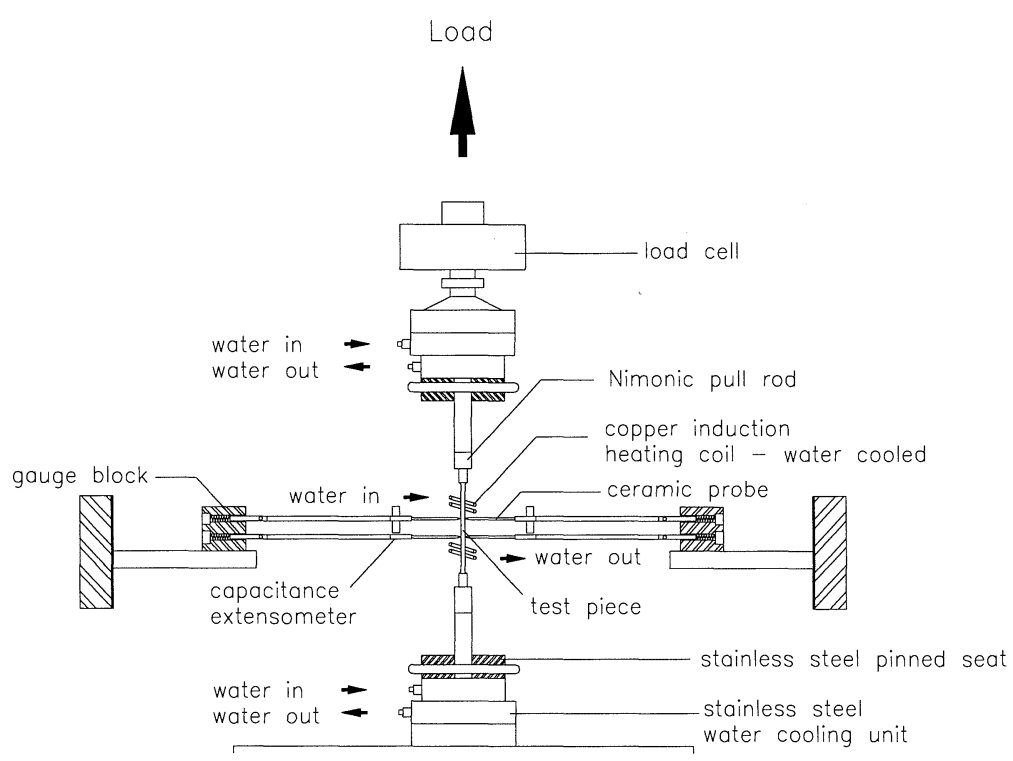

\section{FIGURE 1 Tensile Test Setup}

Each tensile specimen was instrumented with two Capacitec transducers, and five thermocouples, one at each end and in the middle of the gauge length, and one five millimetres outside each end of the gauge length. Tensile coupon dimensions are shown in Figure 2 below.

The coupons were heated using a Cheltenham TR4 induction heater, which was controlled by a Eurotherm controller, using the thermocouple at the bottom of the gauge length as a control thermocouple. During the heating of the tensile coupons, the temperature was ramped to $20^{\circ} \mathrm{C}$ below the test temperature, held for three minutes, then ramped at $10^{\circ} \mathrm{C} / \mathrm{min}$ up to the test temperature, which was maintained for 15 minutes prior to the commencement of the test. The temperature within the gauge length was controlled by manually adjusting the position of the induction heating coils during the test. Very accurate temperatures within the gauge length were possible using this method. The variation was in the order of $3^{\circ} \mathrm{C}$.

During the tests a constant strain rate was maintained to a total strain of $3 \%$ to $5 \%$, followed by a constant crosshead speed. The period of constant strain rate was limited by the $2.5 \mathrm{~mm}$ maximum range of the Capacitec transducers, in conjunction with the spacing between the heating coils and the transducers. Constant crosshead speeds were chosen to either match the initial strain rate $(0.2$ or $0.002 / \mathrm{min})$, or to induce an intermediate strain rate of $0.03 / \mathrm{min}$, in order to investigate the effect of changes in strain rate during a test. Each tensile test proceeded until the test specimen fractured. 


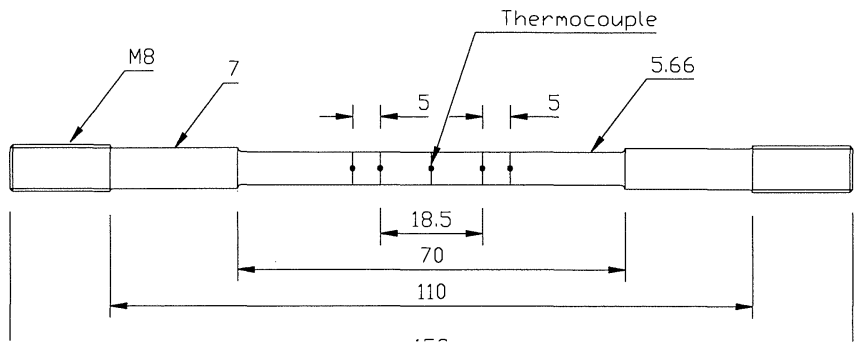

Figure 2 Tensile Test Coupon

The strain was calculated from the mean of the two Capacitec transducer readings. Outside the range of the transducers, the crosshead movement was used to calculate the strains. A difficulty arose as to the correct gauge length to use when calculating the strains from the crosshead movement, mainly due to the temperature variation of the test coupon outside the original gauge length.

\subsubsection{Test Results}

The stress-strain curves for some of the elevated temperature tensile tests are shown in Figure 3. Considerations of space and clarity prevent the inclusion of all test results.

From Figure 3 it can be seen that the effect of different strain rates is negligible at temperatures of $400^{\circ} \mathrm{C}$ and below, but increasingly significant as the temperature rises from $450^{\circ} \mathrm{C}$ to $600^{\circ} \mathrm{C}$. This would be anticipated as this temperature range corresponds to the onset of creep in steel. As the temperature increases to $400^{\circ} \mathrm{C}$ both the maximum stress and the rate of strain hardening are either greater than or equal the ambient temperature values, while between $400^{\circ} \mathrm{C}$ and $600^{\circ} \mathrm{C}$ they both reduce markedly, with an almost elastic-plastic response at $600^{\circ} \mathrm{C}$.

For those tests where the intermediate strain rate was used for the secondary part of the tensile test, the curves were adjusted according to the step change in stress due to the change in strain rate. This was necessary as stress-strain data for the FEA simulations was required up to failure at each strain rate. This approach is supported by the results for the relevant tests, such as the $500^{\circ} \mathrm{C}$ and $600^{\circ} \mathrm{C}$ tests shown in Figure 3, where tests at both the high and low initial strain rate converge to the same stress-strain path at the intermediate strain rate.

The initial modulus, $E$, was calculated from the average of the two Capacitec transducer readings, with the average values for both strain rates and all tests at each temperature shown in Table 1. Accurate determination of the initial modulus was difficult due to the very small linear part of the stress strain curve. No relationship between modulus and strain rate was observed in these tests. 


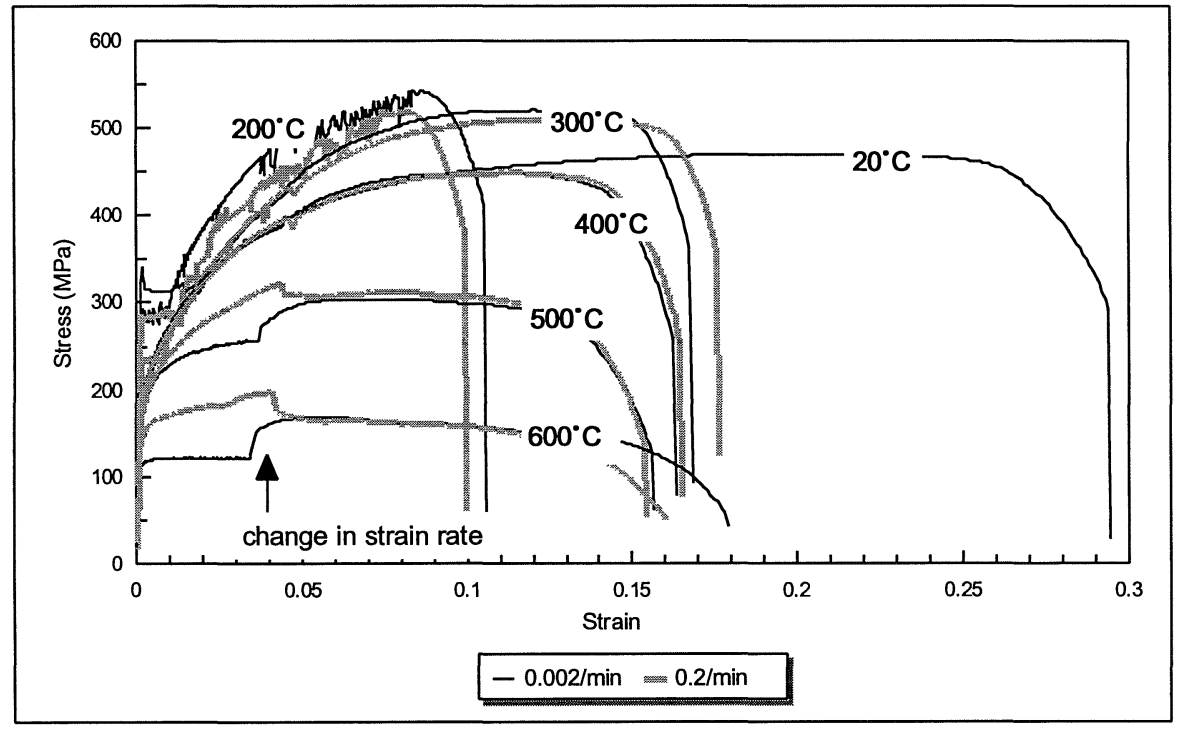

FIGURE 3 Stress-strain test results at strain rates of $0.002 / \mathrm{min}$ and $0.2 / \mathrm{min}$

TABLE 1 Average Elastic Modulus

\begin{tabular}{|c|c|c|c|}
\hline $\begin{array}{c}\text { Temperature } \\
\left({ }^{\circ} \mathrm{C}\right)\end{array}$ & $\begin{array}{c}\text { Elastic Modulus } \\
(\mathrm{MPa})\end{array}$ & $\begin{array}{c}\text { Temperature } \\
\left({ }^{\circ} \mathrm{C}\right)\end{array}$ & $\begin{array}{c}\text { Elastic Modulus } \\
(\mathrm{MPa})\end{array}$ \\
\hline 20 & 204,247 & 450 & 160,868 \\
200 & 191,736 & 500 & 151,778 \\
300 & 178,153 & 550 & 144,448 \\
350 & 190,758 & 600 & 128,012 \\
400 & 180,720 & 650 & 122,105 \\
\hline
\end{tabular}

\subsection{Stub Column Tests}

A series of 12 elevated temperature column tests were carried out at BHPR-ML on $1200 \mathrm{~mm}$ long, 150UC23.4 universal column sections, partially heated over $700 \mathrm{~mm}$. A $1000 \mathrm{KN}$ Instron hydraulic actuator testing machine, employing displacement control, was used for all the tests. All tests were carried out using a constant crosshead speed, which was calculated to give an average strain rate of approximately $0.002 / \mathrm{min}$ in the column. The column sections used in the tests were from the same batch as those used for the tensile coupon tests. A schematic of the test setup is shown in Figure 4 below. 




FIGURE 4 Test rig for Stub-column tests

The column sections were heated using $700 \mathrm{~mm}$ long, 60 volt, ceramic insulated electrical resistance heating pads. Heating pads were attached to each flange, and to one side only of the web. Each heating pad consisted of three heating elements, with each element controlled by a thermocouple attached to the column at the centre of the element, ie, nine control circuits were used. The heating pads were held in position by ductile wire, before being wrapped in two layers of $25 \mathrm{~mm}$ thick ceramic fibre insulating blanket. The ends of the column sections were effectively fixed, as they were located in a $3 \mathrm{~mm}$ deep slot machined into the face of the water cooled spacers.

The temperatures in the column were recorded using $63 \mathrm{~K}$ - type thermocouples, located at nine cross-sections along the column; $30 \mathrm{~mm}$ in from the column ends, at each end and in the middle of the $700 \mathrm{~mm}$ heated length, and at the centre and each end of the individual heating elements. Seven thermocouples were located at each cross-section; at the flange tips, flange-web junction and the web center-line.

Two LVDT axial extensometers were attached to the flanges of the columns on the flange/web junction, over a gauge length of $760 \mathrm{~mm}$, to measure axial displacements over the 
heated length. The platen movement of the testing machine was also recorded for each test. Lateral displacements were not measured during the tests due to the difficulty in locating the point of buckling, and the introduction of higher temperature gradients as a result of penetrations in the insulating blanket.

The tests were carried out at constant temperatures of $20^{\circ} \mathrm{C}, 300^{\circ} \mathrm{C}, 400^{\circ} \mathrm{C}, 500^{\circ} \mathrm{C}$ and $600^{\circ} \mathrm{C}$. The columns were maintained at the test temperature for a minimum of one hour.prior to the commencement of the test, to ensure as uniform a temperature as possible over the heated section of the column.

\subsubsection{Stub Column Test Results}

All the column sections tested exhibited local buckling of the plate elements, and had a stable post-buckling load-deflection response. Refer to Figures 5 to 9 . Each of the graphs show the test result, and the FEA simulations with a geometrically perfect mesh and various degrees of an initial imperfection in the geometry of the column. See Section 3.2 regarding the shape and degree of imperfection, denoted Imp in Figures 5 to 9. It is interesting to note that the point of buckling was at approximately $10 \mathrm{~mm}$ total axial displacement for all tests up to and including $500^{\circ} \mathrm{C}$, with a significant drop to approximately $8 \mathrm{~mm}$ total axial displacement at $600^{\circ} \mathrm{C}$.

The heating method used for the elevated temperature column tests resulted in high temperature variations in the order of $196^{\circ} \mathrm{C}$, within the heated section of the column at $600^{\circ} \mathrm{C}$. These were due to the end losses from the columns, and the distribution of temperature over the individual heating pads, with the highest temperatures at the centre of each pad.

A small number of the test columns deformed into an overall buckled shape about the minor axis of the section, that resembled the Euler buckling shape that would be expected for a slender column. However, Euler buckling was not possible in these "stocky" column sections, since $\mathrm{L}_{\mathrm{e}} / \mathrm{r}=33$. The "overall" deformation was initiated by a combination of temperature variation, load eccentricity, and an imperfection caused by the asymmetric local buckling of the plate elements. For example, in one of the ambient temperature tests, where the column was visible during the test, the column initially exhibited local buckling on one flange only, probably due to load eccentricity, which resulted in a further imperfection that initiated overall deformation about the minor axis of the column section.

This behaviour was also observed in the latter stages of some of the elevated temperature column tests. Asymmetric local buckling of the plate elements, in combination with an imperfection due to the temperature gradients generated by having a heating pad on only one side of the web, resulted in an imperfection sufficient to cause this overall deformation. The eccentric loading of the column sections was due to inaccurate machining of the column ends. If the column ends were not square, the lower end of the column would have to translate to ensure full area contact between the column end and the loading platen. This was not possible because of restraint due to the axial loading of the column. Measurements of the error in machining the column ends indicated a maximum error of $0.35 \mathrm{~mm}$ across the width of the flanges. The "end effects" caused by these errors in machining can be seen when the initial axial stiffness of the column in the tests (calculated from the loading platen movement), is 

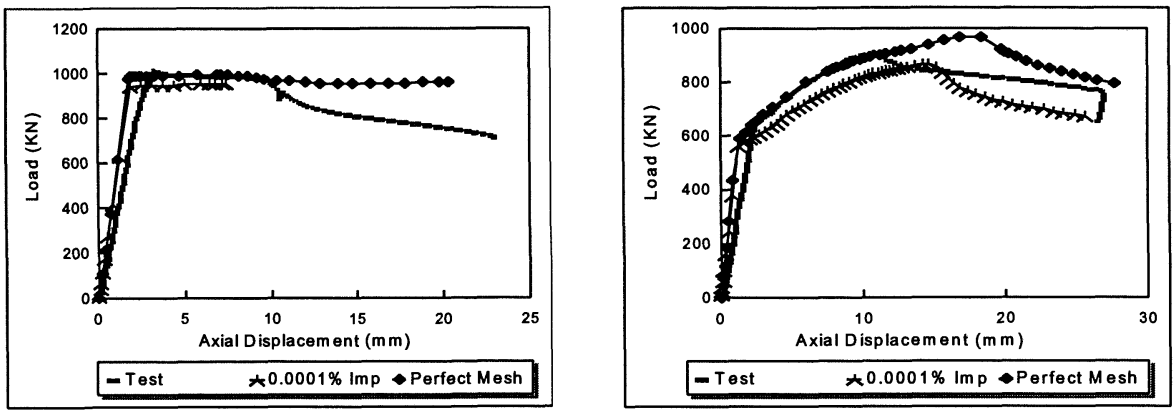

FIGURE $520^{\circ} \mathrm{C}$ Test and simulation. FIGURE $6300^{\circ} \mathrm{C}$ Test and simulation.
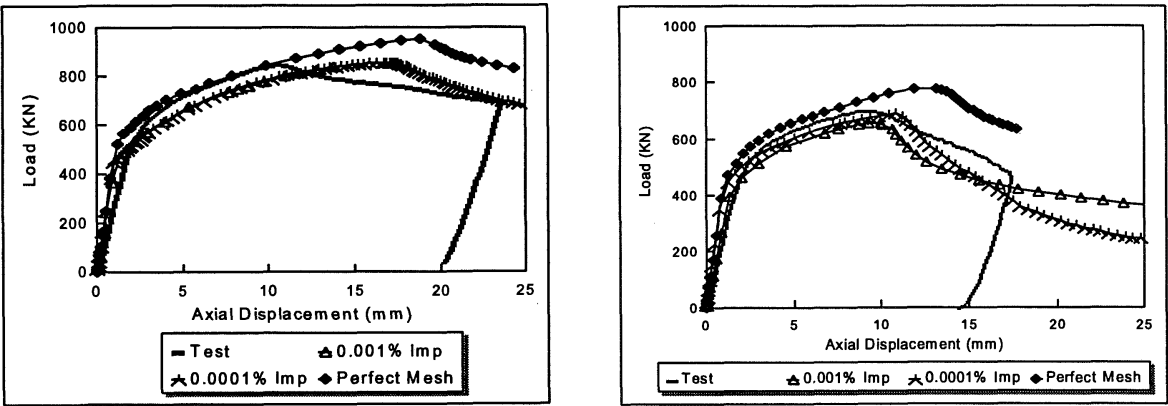

FIGURE $7400^{\circ} \mathrm{C}$ Test and simulation. FIGURE $8500^{\circ} \mathrm{C}$ Test and simulation.

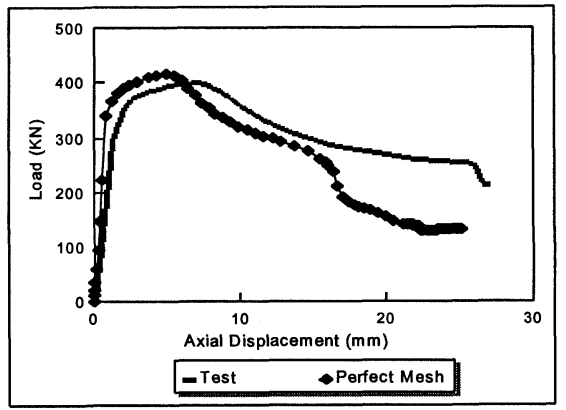

FIGURE $9600^{\circ} \mathrm{C}$ Test and simulation. 
compared with the simulation (Figure 9). In general, the values from the platen movement are approximately $60 \%$ of those calculated from the axial extensometer readings. The initial axial stiffness calculated from the axial extensometer readings are within $2 \%$ of the values returned by the FEA.

The lower axial stiffness calculated from the platen movement is due to a combination of bending deformation as a result of load eccentricity, and local yielding and crushing of the lower column end as the load increases, bringing more of the cross-sectional area in contact with the loading platen. The two effects appear to cancel each other out, and result in an initial linear axial stiffness for all tests at all temperatures. The loading platen displacement was used in graphing the test results, since the analysis of the column was for the total test column length.

\section{ANALYSIS}

\subsection{Heat Transfer Analysis}

The average thermocouple temperatures recorded during the elevated temperature column tests were used in a steady state heat transfer analysis of the column section, to calculate all nodal temperatures for the discretised column. These nodal temperatures were then used to determine the relevant material properties for each element.

\subsection{Nonlinear Static Analysis}

A finite element analysis, using the program ABAQUS [8], was carried out to simulate the results of the experimental testing program. The displacement controlled analysis used shell elements, allowed for Euler, torsional and local buckling, and incorporated both geometric and material nonlinearity. The shell elements used in the analysis were 4 node doubly curved elements, suitable for thick or thin shell applications, allowed for both changes in dimension, finite membrane strains, and transverse shear output. The cross sectional behaviour of the shell elements was calculated by numerical integration using Simpsons rule, providing complete generality in material modelling. Five integration points through the thickness of the element were found to be sufficient. A relatively course mesh of $6 \times 48$ elements in each flange and the web were found to be computationally efficient and sufficiently accurate. The material properties used in the analysis were obtained from the elevated temperature tensile tests.

The large temperature variations in the column section during testing resulted in localisation of displacements in the hottest areas of the column in the initial stage of the tests, ie, deformation occurred predominantly in the areas of high temperature. Further localisation occurred after the onset of buckling, ie, within the buckled section due to the drop in membrane stiffness. These localised displacements, particularly in the $500^{\circ} \mathrm{C}$ and $600^{\circ} \mathrm{C}$ column tests, resulted in higher strain rates in these parts of the column, effectively increasing the load the column could carry at any stage (Figure 3). FEA simulations using the stress-strain data at the average strain rate induced in the test column $(0.002 / \mathrm{min})$, resulted in loads significantly lower than those achieved in the tests. Strain rate dependent material properties were implemented in the analysis to account for these effects. 
Skinner [9] reported an almost linear relationship between stress and log strain rate for six strain rates between $0.0001 / \mathrm{min}$ and $0.1 / \mathrm{min}$. This relationship was used to determine stress-strain curves for strain rates of $0.0001 / \mathrm{min}$ and $0.1 / \mathrm{min}$, based on the $0.002 / \mathrm{min}$ coupon tensile test results. The stress-strain data at these four strain rates $(0.2,0.1,0.002$, $0.0001 / \mathrm{min}$ ), was implemented in the analysis in tabular form, with linear interpolation used to determine intermediate data points.

To determine the imperfection to be used in the nonlinear static analysis, a linear elastic buckling analysis was carried out on the straight or geometrically perfect column, with the temperature profile in the column taken from a test. The first or second buckling mode shape was then transferred to the nodal co-ordinates, with the maximum displacement being specified as a percentage of the nominal web thickness $(6.1 \mathrm{~mm})$. The percentage used ranged from $0.0001 \%$ to $10 \%$, ie, maximum nodal displacement ranging from $6.1 \times 10-6 \mathrm{~mm}$ to 0.61 $\mathrm{mm}$. Each of the columns was also analysed with a geometrically perfect mesh.

The comparison between the load deflection curves for the tests and those from the FEA can be seen in Figures 5 to 9. Good agreement was obtained between the model and the test results, both from the initial load application through to and including the "softening" load/deflection curve in the postbuckling range, especially for the $500^{\circ} \mathrm{C}$ and $600^{\circ} \mathrm{C}$ tests. (See Figures 8 and 9 respectively). The FEA results do not appear to be very sensitive to the assumed imperfection. In general, the use of a perfect mesh for the FEA simulation results in a load-deflection curve in very good agreement with the test up to the point of buckling, but then over-estimates both the buckling load and displacement, as well as the post buckled load carrying capacity of the column. The introduction of an imperfection in the mesh generally results in an under-estimation of the column capacity, but more accurately predicts both the point of buckling and the post buckled response.

The temperature variation in the column at $600^{\circ} \mathrm{C}$ resulted in a temperature induced imperfection sufficient to accurately model the test result using a geometrically perfect mesh (Figure 9). The FEA simulation over-estimates the initial load carrying capacity of the column, possibly due to an imperfection in the column tested, but accurately predicts the point of buckling and the early post bucking response. The degree of imperfection required to accurately model the tests appears to increase as the test temperature reduces, probably due to the lower temperature variations at the lower temperatures. The use of a $10 \%$ imperfection, however, was found to be invalid. The lower initial axial stiffness due to the previously mentioned "end effects", with test displacements being the loading platen movement, is clearly seen for all test results.

The buckled shape predicted by the FEA simulation is also in good agreement with the test results. Figure $10 \mathrm{a}$ depicts the buckled shape of a column from a FEA simulation of a column tested at $600^{\circ} \mathrm{C}$, shown in Figure $10 \mathrm{~b}$. The displacements in Figure $10 \mathrm{a}$ are the actual, or unscaled displacements at the end of the analysis. In many of the simulations, the column initially buckled with two half-wave buckles, which localised into a single half-wave buckle 


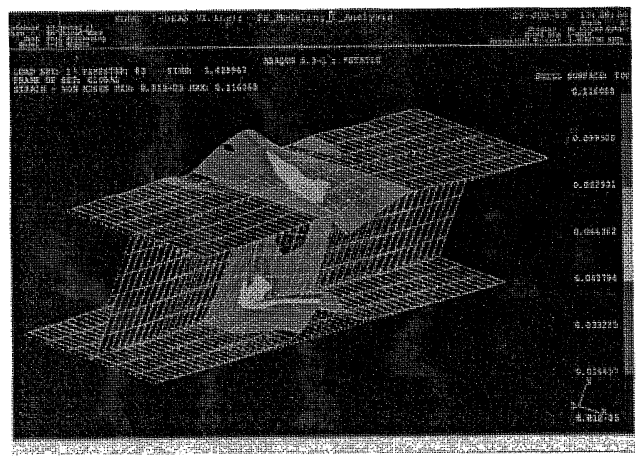

FIGURE 10a FEA of test column at $600^{\circ} \mathrm{C}$

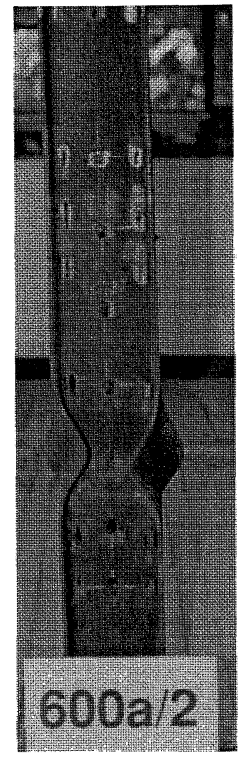

FIGURE 10b Test

in the post-buckling range. This behaviour was also noticed in one of the ambient temperature buckling tests.

\section{4} CONCLUSIONS

The material properties for Grade 250 150UC23.4 universal column section were obtained from a series of tensile coupon tests at various temperatures and at different strain rates. These properties were incorporated into a FEA to simulate the results of stub-column buckling tests at temperatures up to $600^{\circ} \mathrm{C}$. Good agreement was obtained between the tests and the FEA load-deflection curves, when a small assumed imperfection of geometry is taken into account. This would indicate that the incorporation of rate dependent material properties is a sufficiently accurate method to predict the behaviour of steel columns at elevated temperatures for a short period of time, or at lower temperatures for an extended time, ie, when creep is not significant. The main advantage of this method is the ease with which these rate dependent material properties can be incorporated, and the reduced requirement for testing to obtain creep data.

For this method to obtain accurate results where creep is significant, ie, at elevated temperatures for an extended period of time, material properties data obtained at very low strain rates are required. These low rates would implicitly include more creep. An alternate 
method of analysing a column at elevated temperature for extended time is to incorporate creep data into a FEA. The investigation is continuing in this direction, with the completion of a series of elevated temperature creep tests to determine relevant creep data, which is currently being incorporated into a FEA model to analyse a column under these conditions. This work is not reported in this paper.

\section{ACKNOWLEDGMENT}

The authors wish to thank the BHP Structural Steel Development Group, and BHP Research Melbourne Laboratories for their support for the project, Dr I. D. Bennetts and Mr. M. Skarajew of BHP Research Melbourne Laboratories, Prof. V. Beck and Mr S.A. Young of Victoria University of Technology, for their significant input to the project.

\section{REFERENCES}

1 Warren Centre, "Project Report" and "Technical Papers, Books 1 and 2", Fire Safety and Engineering Project, The Warren Centre for Advanced Engineering, The University of Sydney, December, 1989.

2 Bennetts, I.D., Almand, K.H., Thomas, I.R., Proe, D.J and Lewins, R.R., "Fire in Carparks", BHP Melbourne Research Laboratories Report Number MRL/PS69/89/006, August 1989.

3 Culver, C., Aggarwal, V. \& Ossenbruggen, P., "Buckling of Steel Columns at Elevated Temperatures", Journal of STRUCTURAL DIVISION, ASCE, April 1973, pp 715-726.

4 Burgess, I. W., Olawale, A. O. \& Plank, R. J., "Failure of Steel Columns in Fire", FIRE SAFETY JOURNAL, Vol 18, No 2, 1992, pp 183-201.

5 Olawale, A. O. \& Plank, R. J., "The Collapse Analysis of Steel Columns in Fire Using a Finite Strip Method", INTERNATIONAL JOURNAL FOR NUMERICAL METHODS IN ENGINEERING, $\quad$ Vol 26, 1988, pp 2755-2764.

6 Steel Construction Industry Forum, "Structural Fire Engineering - Investigation of the Broadgate Phase 8 Fire", STRUCTURAL FIRE ENGINEERING, June 1991

7 Standards Australia, Australian Standard AS1391 - Methods for Tensile Testing of Metals, Standards Australia, 1991.

8 Hibbit, Karlson \& Sorensen, ABAQUS User's Manual, Hibbit Karlson \& Sorensen, Inc., 1994.

9 Skinner, D.H., "Mechanical Behaviour oi Steel During Fire", M. App. Sci. Thesis, University of Melbourne for , 1974. 